\title{
SOBRE JUSTIÇA RESTAURATIVA E FRATERNIDADE: QUALIFICANDO O ACESSO À JUSTIÇA
}

\author{
Camila de Cerqueira Silva Macário ${ }^{1}$ \\ Gabriela Maia Rebouças ${ }^{2}$
}

\section{RESUMO}

O estigmatizante modo de solucionar demandas não ressignificam os conflitos vivenciados, dificultando pacificação social. Nesse sentido, a efetivação da justiça depende da modificação nas maneiras tradicionais de pensar e de fazer justiça. Este artigo tem o objetivo de discutir e apresentar, a partir de levantamento bibliográfico, uma análise-argumentativa acerca da pertinência da relação entre justiça restaurativa, fraternidade, acesso à justiça e direito ao desenvolvimento.

Palavras-chave: Direito ao Desenvolvimento; Justiça Restaurativa; Acesso à Justiça; Fraternidade

\section{ABOUT RESTORATIVE JUSTICE AND FRATERNITY: QUALIFYING ACCESS TO JUSTICE}

\begin{abstract}
:
The stigmatizing way of solving demands doesn't significances the conflicts experienced, making difficult social pacification. In this sense, the effectiveness of justice depends on the adjusting in the traditional ways of thinking and doing justice. This article has the objective of discussing and presenting, from a bibliographical survey, an argumentative analysis about the pertinence of the relationship between restorative justice, fraternity, access to justice and the right to development.
\end{abstract}

Keywords: Right to Development; Restorative Justice; Access to Justice; Fraternity

\section{INTRODUÇÃO}

O desenvolvimento humano pode ser concebido de diferentes formas, ou seja, vários jogos podem ser vivenciados para alcançar o mesmo objetivo. Porém, nem sempre será possível a mesma qualidade no resultado. A sociedade contemporânea liberal tem

\footnotetext{
${ }^{1}$ Mestranda em Direitos Humanos pela Universidade Tiradentes (UNIT/SE). Bolsista pela Coordenação de Aperfeiçoamento de Pessoal de Nível Superior (CAPES). Formação em Mediação Judicial pelo Tribunal de Justiça do Estado da Bahia. Bacharela em Direito pela Universidade do Estado da Bahia. E-mail: cmscerqueira@yahoo.com.br

2 Doutora em Direito pela UFPE. Pós Doutora pelo Centro de Estudos Sociais da Universidade de Coimbra 2015/2016. Professora e Pesquisadora no Programa de Pós-Graduação em Direito-Mestrado em Direitos Humanos da Universidade Tira- dentes - UNIT (SE) e Professora no Mestrado em Sociedade, Tecnologias e Políticas Públicas do Centro Universitário Tiradentes (AL). E-mail: gabrielamaiar@ gmail.com
} 
experimentado diversas formas de realização de seus valores, com momentos de ampliação e retração de direitos. Liberdade, igualdade, justiça social, boa economia e democracia seguem um caminho coletivo dinâmico, de (re) construção constante, mas sempre apoiados em concepções de desenvolvimento. Neste sentido, seguimos problematizando o acesso à justiça como um ponto fundamental do direito ao desenvolvimento nas sociedades contemporâneas, focado aqui na interseção entre justiça restaurativa e fraternidade

Separar direitos individuais e direitos coletivos já não tem mais espaço na atual ideia de justiça. Nesse sentido, participação política e diálogo constituem pontos centrais no caminho para a prática dos direitos humanos, pensados numa perspectiva crítica e não meramente normativa. Assim, alcançar desenvolvimento vai além das letras frias dos documentos normativos internacionais e nacionais. É preciso compreender que apesar de os direitos humanos não serem universais, já que cultura, modos de vida e maneiras de ser são inteiramente diferentes no mundo, eles podem ser compartilhados, por autonomia e adesão, abrangendo uma rede humana compreensiva, libertadora, lutadora e em constante transformação social.

A partir dessa outra concepção de mundo, a justiça precisa ser mais mediadora, dialogal, respeitosa, promovendo equilíbrio entre todos os seus participantes de acordo com seus lugares e posições. A disputa e a competição dão lugar a ressignificação do conflito, e quase sempre das próprias partes envolvidas. É diante do cenário desenvolvimentista que este trabalho pretende apresentar a justiça restaurativa como uma concepção fraterna e justa de acesso à justiça.

Muitas indagações são feitas à justiça brasileira atual: por que o tempo das ações ultrapassam o tempo imaginável? Por que as custas são tão altas? Por que muitas questões, mesmo passando pelo crivo da justiça, ainda permanecem em conflito fora dos tribunais? Será que a maneira como resolvemos os conflitos é adequada? Outras tantas perguntas poderiam ser produzidas diante da gama de demandas judiciais e extrajudiciais. Uma questão evidente é que o modo de se fazer justiça é problemático, pois estigmatiza, negativiza, e trata com frieza as questões humanas.

Buscando compreender os movimentos de renovação de justiça, do seu acesso qualificado, o trabalho apresentará, a partir de um olhar desenvolvimentista humano e fraterno, o fenômeno da justiça restaurativa como forma de um melhor acesso à justiça, mais adequado e efetivo às relações humanas e seus conflitos. 
O objetivo em mente é apresentar a justiça restaurativa como um novo modo de se vivenciar a justiça. Não se pode deixar de apontar que há uma problemática que acompanha as concepções de justiça na história, tensionada entre um objeto idealizado e as práticas concretas, que, na imanência da ação, mostra-se cruel ou redentora com todas as forças. A (in)justiça embora de tão difícil delimitação, é de fácil sentir.

A estrutura metodológica deste trabalho foi desenhada buscando dados e ideias através sobretudo da pesquisa bibliográfica, e desenvolvida como uma análise-argumentativa acerca da pertinência da relação entre justiça restaurativa, fraternidade, acesso à justiça e direito ao desenvolvimento.

Nesse contexto, primeiramente, apresentar-se-á o direito ao desenvolvimento, um diagnóstico geral do mesmo, focando o olhar sobre a fraternidade e o acesso à justiça como vertentes importantes tanto para esse direito quanto para o tema justiça restaurativa.

Em seguida, mostraremos a justiça restaurativa de maneira a delinear seus primeiros passos, suas conceitualizações e as principais concepções - encontro, transformação e reparação. Ao final faremos uma relação aproximada entre justiça restaurativa e acesso à justiça, apresentando a justiça restaurativa como possibilidade teórica e prática de alcance da justiça.

\section{DIREITO AO DESENVOLVIMENTO COMO EXPRESSÃO DE FRATERNIDADE E JUSTIÇA}

O Direito ao Desenvolvimento historicamente está atrelado à criação do sistema contemporâneo de direitos humanos internacionais, inaugurado com a Declaração Universal dos Direitos Humanos, em 1948, como fruto da criação da Organização das Nações Unidas em 1945.

A partir disso, o desenvolvimento foi aparecendo nos documentos internacionais de forma tímida e aos poucos, paralelo ao reconhecimento e independência de países colonizados ou nomeados como subdesenvolvidos. A luta desses países para reconhecimento de sua hipossuficiência, constituída ao longo de séculos de exploração, que redundaram no desenvolvimento de uns poucos países, mas no empobrecimento alargado de grande parte da população mundial, também foi estratégia de suma importância para o fortalecimento do direito ao desenvolvimento. 
A primeira pessoa a utilizar a expressão "Direito ao Desenvolvimento" foi Etiene Keba M Baye, de acordo com a doutrina majoritária, em uma conferência inaugural do Curso de Direitos Humanos do Instituto Internacional de Direitos do Homem de Estrasburgo, em 1972. Depois de alguns anos, a Resolução n. 4 (XXXIII) da Comissão de Direitos Humanos, de 21 de fevereiro de 1977 reconheceu o direito ao desenvolvimento como direito humano. (ANJOS FILHO, 2013, p. 94)

Outro importante documento para esse direito foi a Declaração das Nações Unidas sobre Direito ao Desenvolvimento (1986), advinda dos estudos sobre desenvolvimento realizados por um grupo de trabalho da Comissão de Direitos Humanos.

$\mathrm{O} \S 1^{\circ}$ do art. $1^{\circ}$ dessa declaração $\operatorname{diz}^{3}$ :

§1. O direito ao desenvolvimento é um direito humano inalienável, em virtude do qual toda pessoa e todos os povos estão habilitados a participar do desenvolvimento econômico, social, cultural e político, para ele contribuir e dele desfrutar, no qual todos os direitos humanos e liberdades fundamentais possam ser plenamente realizados. (Grifos nossos)

Como se apreende do referido recorte, esse direito foi consagrado como direito humano inalienável e abrangente, isso demonstra que tal direito é uma expressão da terceira dimensão dos direitos humanos, onde a fraternidade deve ganhar destaque.

Assim, o direito ao desenvolvimento apóia e reforça os outros direitos humanos, destacando a magnitude e aspecto prático de todos eles, e ainda, "não ameaça o consenso existente entre os direitos humanos, mas permite como instrumento de uma interpretação progressiva e criativa, que esses direitos dêem conta de novas circunstâncias e percepções. " (ANJOS FILHO, 2013, p. 127)

Nesse sentido, três premissas de Ignacy Sachs (1986) são centrais para o desenvolvimento e contribuem para o alcance do direito ao desenvolvimento como direito humano: a eficiência econômica, a justiça social e a prudência ecológica. Seguindo esse pensamento, entendemos que o ecodesenvolvimento elaborado pela autora junto ao sentido humanístico que se deve dar ao desenvolvimento, completa o significado do direito ao desenvolvimento.

Também no sentido humano, está o pensamento de Amartya Sen (2000) que entende o desenvolvimento a expansão das liberdades reais das pessoas, o que seria para ele tanto fim

\footnotetext{
${ }^{3}$ Uma versão em português pode ser encontrada em: <http://www.direitoshumanos.usp.br/index.php/Direito-aoDesenvolvimento/declaracao-sobre-o-direito-ao-desenvolvimento.html>, acesso em 08 de junho de 2017.
} 
quanto instrumento do desenvolvimento. Assim, a liberdade tem papel constitutivo e instrumental no direito ao desenvolvimento.

Um dos aspectos importantes do desenvolvimento, é o poder de pedir e reclamar as incongruências sociais, quais sejam elas. Ter a liberdade de acessar a justiça adequada, célere e efetiva é relevante para o Estado se afirmar como desenvolvido, por ser um dos direitos mais básicos disponíveis à população, por ser o direito que mais ajuda a promover todos os outros, por promover a liberdade geral das pessoas.

Para tanto, o acesso à justiça, deve ser revisto de tempos em tempos para que se adeque às transformações da sociedade, como tem sido com relação aos conflitos de pequeno porte tanto na seara civil e penal quanto na infância e juventude, espaços onde mediação, justiça restaurativa e conciliação estão em destaque e são buscadas constantemente. Isto porque são meios que parecem ser adequados para se chegar à justiça, acessá-la não mais tradicionalmente, uma vez que as antigas soluções, em parte significativa dos casos, parecem não mais efetivas - se é que um dia foram.

Portanto, em sentido fraterno, esse direito humano é feito e refeito para os grupos sociais, para a coletividade, tendo em vista a harmonia e solidariedade entre os planos individual e coletivo; internacional e nacional.

\subsection{Fraternidade}

Antes de continuar na trajetória deste artigo, necessário posicionamento se faz quanto ao lugar que este direito está situado dentro do cenário histórico das dimensões dos direitos humanos. Essa localização possibilita entender e ampliar o significado deste "Direito ao Desenvolvimento" (e consequentemente da justiça restaurativa), trazendo sentido à expressão e delimitando-a.

A fraternidade é o eixo central da terceira dimensão de direitos fundamentais/humanos, ainda em fase de consagração, e para alguns destaca-se junto aos direitos de quarta dimensão - não reconhecida por alguns doutrinadores.

Para entendimento, os direitos fundamentais e compreende-se que também os direitos humanos, foram doutrinariamente divididos em dimensões com um intuito didático e como forma de localizar dentro da história em que momento certos direitos estavam em destaque, nas campanhas de resistência dos povos. Assim, apresento de maneira sucinta, por não ser a questão central deste trabalho, as dimensões: primeira, direitos civis e políticos, o 
enfoque é a liberdade; segunda, direitos sociais, econômicos e culturais, o foco aqui é a igualdade; terceira e aqui em destaque, os direitos de solidariedade: o eixo central é a fraternidade entre os povos, o coletivo assume maior importância sem excluir o ser individual; e por fim, a quarta dimensão, os direitos à biotecnologia e à democracia direta. (CUNHA JÚNIOR, 2010) ${ }^{4}$

A terceira dimensão caracteriza-se por direitos protetivos, com titularidade coletiva e/ou difusa. Segurança, paz social, autodeterminação dos povos, solidariedade universal, meio-ambiente equilibrado, comunicação, reconhecimento mútuo de direitos entre os países e desenvolvimento são alguns dos aspectos dessa dimensão, a qual tem a finalidade de preservar a existência humana como um todo, necessitando de uma conjunção de esforços em escala internacional. (CUNHA JÚNIOR, 2010, p. 593)

A partir do contexto, o direito ao desenvolvimento tem se consagrado diante dessa dimensão, especialmente como constitucionalismo fraternal em diversas Cartas Magnas italiana, portuguesa e brasileira. (MACHADO, 2015, p. 10)

Hoje, parte -se para a garantia de direitos que regulamentam a relação homem - todos os homens (terceira dimensão). As dimensões liberal e social direitos (liberdade e igualdade) passaram a se desenvolver adensadas indissociável e reciprocamente entre si, mas catalisadas por direitos de fraternidade. (MACHADO, 2015, P. 13)

Também a Declaração Universal, mesmo promulgada distante do momento de fomento da fraternidade, já trazia a fraternidade expressa em seu artigo primeiro, como impulso de comportamento do ser humano e não apenas de forma generalizada, com sentido apenas conceitual.

Nesse sentido, o desenvolvimento tem terreno fértil para se desenrolar junto à fraternidade - sua essência - uma vez que são dependentes.

\subsection{Acesso à Justiça}

Como já mencionado, o acesso à justiça é um dos mais destacados direitos, por seu caráter alicerçador e basilar numa sociedade. É a garantia dada ao Estado de pedir ou reclamar as "coisas", as situações, sejam elas de ordem material ou imaterial. É a garantia de liberdade

\footnotetext{
${ }^{4}$ Para conhecimento sobre as dimensões dos direitos fundamentais ler: CUNHA JÚNIOR, Dirley da. Curso de Direito Constitucional. Salvador: Editora Podivm, 2010, p. 580-595.
} 
quando esta foi tolhida ou nem mesmo dada. É instrumento de luta e resistência, outras vezes é a única chance de sobrevivência.

Leslie Ferraz (2011, p. 341) apresenta o acesso à justiça como um "sistema capaz de promover uma tutela jurisdicional qualificada", o que quer dizer adequada, efetiva e tempestiva. Diante do acesso à justiça qualificado, o trabalho tomará como papel central a vertente adequação do acesso à justiça, pois aproxima-se do tema justiça restaurativa em destaque, já que nessa concepção de acesso qualificado à justiça, o movimento restaurativo é fenômeno que se insere na terceira onda - um novo enfoque de acesso à justiça - traçada por Cappelletti e Garth (1988).

Mauro Cappelletti e Garth (1988) apresentam em seu livro Acesso à Justiça novo arranjo sobre o tema, o qual ele chama de onda, são três. A primeira onda é a assistência judiciária para os pobres; a segunda, representação dos interesses difusos, e a terceira onda, do acesso à representação em juízo a uma concepção mais ampla de acesso à justiça, um novo enfoque de acesso à justiça.

A primeira onda preocupa-se com estabelecer assistência àqueles que não podem pagar pelos serviços jurídicos, Cappelletti e Garth (1988) enfatizam que o auxílio de um advogado é essencial para explicar leis cada vez mais complexas e procedimentos obscurecidos, e muitas vezes abstratos na análise de uma pessoa leiga.

A segunda onda veio abrir espaço no processo civil para os interesses difusos, pois o processo era visualizado como um litígio entre duas partes, os grupos em geral tinham dificuldade de lutar por interesses que lhes eram comuns. Nessa onda, novas acepções sobre coisa julgada, citação, papel do juiz foi sendo reinterpretada ou até mesmo modificada.

A última onda, partir da qual este artigo se desenrola, é contemplada pelas duas primeiras, sendo a continuação lógica do caminho traçado por Cappelletti e Garth. Nessa etapa, o apelo é por transformações profundas e estruturais no sistema de justiça, novos mecanismos de respostas aos conflitos emergentes das sociedades, desburocratização, mediação de conflitos e maior participação nos processos judiciais são focos centrais desse terceiro movimento renovatório. Assim afirmam Cappelletti e Garth (1988, p. 71), “existem muitas características que podem distinguir um litígio do outro. Conforme o caso, diferentes barreiras ao acesso podem ser mais evidentes, e diferentes soluções, eficientes. ”

As transformações do sistema de justiça organizadas em etapas são as ondas renovatórias, movimento que buscou se concentrar não apenas na norma, mas nas questões sociais em torno de sua formação e das repercussões na sociedade. (FERRAZ, 2011) 
Enquanto tais mudanças foram se dando aos poucos em muitos países, os quais experimentaram em cada etapa as consequências de tais implementações no intuito de responder a uma necessidade de mudança, no Brasil, as três ondas manifestaram-se praticamente juntas, dificultando o desenrolar de uma justiça com acesso qualificado, influenciando na busca pelo direito ao desenvolvimento, já que o acesso à justiça que possibilita a consagração desse direito a partir das reivindicações sócio jurídicas é defectivo. (FERRAZ, 2011)

Nesse diapasão, o Brasil aprovou leis e inseriu reformas no sistema judiciário com o objetivo de transpor os obstáculos do acesso à justiça, porém em contrapartida sufocou as primeiras ondas, que não foram consolidadas.

A Lei dos juizados, 1984 e a Lei da Ação civil pública, 1984 foram aprovadas na década de 80, momento de emergências das ondas renovatórias no Brasil. A Carta Magna também contribuiu para o movimento das ondas, com a ampliação da assistência judiciária, e tratou também dos juizados especiais e da tutela coletiva. E não podemos deixar de citar o Estatuto da Criança e do Adolescente e o Código de Defesa do Consumidor, expoentes também da renovação do acesso à justiça. Nesse sentido, outros movimentos emergiram dentro desse contexto, a mediação e a justiça restaurativa, ambos ainda em estudos e em solidificação na justiça brasileira. Esses movimentos buscam responder questões trazidas à baila pela terceira onda como a burocratização e a não valorização da participação das partes no sistema de justiça.

É preciso reconhecer que as recentes transformações no judiciário brasileiro, muito focadas numa justiça em números, eficiente e econômica, estimula as múltiplas portas por onde uma justiça restaurativa pode entrar, mas não exatamente objetivando uma condição mais humana, mas sobretudo mirando em desafogar o próprio judiciário. Neste sentido, não se deve desconsiderar que o movimento que aqui inserimos de aproximar a fraternidade, o desenvolvimento da justiça restaurativa encontra na lógica numérica do mundo atual, algum obstáculo.

Feita esta ressalva, em seguida apresentamos dentre as diversas opções citadas a justiça restaurativa, que pode ser compreendida como uma alternativa às soluções tradicionais penais para crimes ou infrações. E, ainda, enxerga-se, uma oportunidade de fomentar o acesso à justiça de forma qualificada, impulsionando o desenvolvimento brasileiro. Acreditar é preciso. 


\section{JUSTIÇA RESTAURATIVA, RENOVAÇÃO E DESENVOLVIMENTO}

\subsection{Situando a justiça restaurativa}

A justiça restaurativa, tal como é compreendida hoje, emergiu a partir da criminologia crítica, entre outras vertentes, sendo fruto de uma complexa construção experimental e teórica ocorrida desde a década de 60 do século passado. Porém, os precursores do movimento restaurativo estão dissociados no tempo e no espaço, com previsões de suas origens nas comunidades comunais da Europa e nos povos colonizados da África, da Ámérica do Sul e do Norte, da Áustria e da Nova Zelândia. (JACCOUD, 2005)

Em virtude de essas sociedades privilegiarem a união do grupo, as práticas de resolução de conflitos tinham por objetivo restaurar o equilíbrio rompido com a transgressão de uma norma. Sobrepunha-se, dessa forma, o coletivo sobre o individual, apesar de não terem sido excluídas formas punitivas como a pena de morte. A tendência era não deixar o grupo se desfazer, mas preservá-lo. (JACCOUD, 2005)

As comunidades nativas e comunais tinham grande preocupação com o papel que cada indivíduo exercia perante o corpo social no qual estava inserido, sendo assim favorecia o desenvolvimento de diversas práticas como diálogo, negociação e outras práticas opostas à punição pura.

Como aponta Jaccoud (2005), antes mesmo da primeira era cristã, alguns Códigos já traziam em si práticas restaurativas ou negociais, sendo que o Código de Hammurabi (1700 a.c) e o de Lipit - Ishtar (1875 a.c) prescreviam medidas de restituição para os crimes contra os bens e o Código sumeriano e o de Eshunna, restituição nos casos de crime de violência.

Os Códigos e as sociedades antigas utilizavam como que "pedaços de uma justiça restaurativa”, pois apenas algumas práticas e alguns casos tinham um tratamento restaurativo, sendo que com o tempo, com o fenômeno de centralização de poderes e com o surgimento do Estado tais práticas foram desaparecendo, sufocadas pelas leis modernas.

A existência de vestígios de uma "justiça negocial" nos povos antigos contribuiu para a formação do modelo restaurativo moderno e contemporâneo. Isto porque uma prática anterior, mesmo que incipiente, já denota experiência, confirmando que o modelo de Justiça Restaurativa não é uma construção fora de contexto.

A justiça restaurativa, desde os anos 60, tornou-se o alvo de uma construção heterogênea, experimental e teórica, em vários lugares do mundo, inclusive no Brasil. Assim, 
vários autores como Zehr e Pallamolla permitem dar conta desta heterogeneidade, tanto no plano teórico quanto no plano prático, com suas diversas modalidades e momentos processuais de implementação.

Cabe enfatizar, então, que a "justiça restaurativa" não constitui um modelo único de justiça. Dentre suas acepções é possível enfatizar, por exemplo, a reparação do dano, a resolução do conflito, ou ainda a transformação da relação ou dos sujeitos envolvidos. Não é nem fundamental que haja a conciliação ou reconciliação entre os envolvidos no ato delituoso. Assim é necessário compreender qual modelo de justiça restaurativa prevalece nos casos específicos, entendendo que poderá haver modalidades peculiares onde os principais objetivos - reparação, resolução do conflito e transformação - não sejam mutuamente exclusivos.

Sobre o conceito de Justiça Restaurativa, sinaliza Jaccoud (2005, p. 169):

[...] a justiça restaurativa é uma aproximação que privilegia toda a forma de ação, individual ou coletiva, visando corrigir as consequências vivenciadas por ocasião de uma infração, a resolução de um conflito ou a reconciliação das partes ligadas a um conflito.

Existe dificuldade em categorizar os diversos conceitos do tema, pois como a prática se deu antes e durante a categorização conceitual, as definições que já existem parecem incompletas diante de sua multiplicidade. Porém, o que parece negativo não o é, já que este modelo de Justiça é um dos poucos que permite que a evolução do Direito ocorra paralelamente - ou quase - com as questões advindas da sociedade.

Diante desse contexto é que se faz pertinente apresentar uma reflexão interessante trazida por Howard Zehr. Após este autor estudar e presenciar práticas de Justiça Restaurativa, ele consegue chegar a uma "definição" da mesma pelo o que ela não é.

Assim, a justiça restaurativa não tem como objeto principal o perdão ou a conciliação; não tem por objetivo principal reduzir a reincidência ou as ofensas em série; não é um programa ou projeto específico; não foi concebida para ser aplicada a ofensas comparativamente menores ou ofensores primários; não é algo novo nem se originou nos Estados Unidos; não é uma panaceia nem necessariamente um substituto para o processo penal; não é necessariamente uma alternativa ao aprisionamento; não se contrapõe necessariamente à justiça retributiva. (ZEHR, 2012) 
Este exaustivo quadro produz uma série de consequências: flexibilidade, liberdade e abertura. Na mesma linha de Jaccoud, outros autores conceituam a justiça restaurativa, diferenciando-se pela concepção que adotam: de encontro, de reparação ou de restauração.

Para Braithwaite, a justiça restaurativa é forma de lutar contra injustiça e contra a estigmatização. Ele entende que é importante a busca da redução das injustiças e não apenas dos delitos, conflitos etc. "Aspira oferecer direções práticas sobre como nós, cidadãos democráticos, podemos levar uma boa vida por meio da luta contra a injustiça. " (Braithwaite apud PALLAMOLLA, 2009)

As concepções de justiça restaurativa são das mais variadas, porém importante destacar três, apresentadas por Pallamolla (2009) e que resumem a ideia geral do instituto: reparação, transformação e encontro.

a) Concepção da reparação: O dano causado à vítima deve ser reparado. Para isso, várias atitudes e práticas poderão ser usadas pelo ofensor para reparar a vítima, sem necessidade de dor ou medo. Outra face da reparação é a oportunidade de o ofensor não sair da comunidade para rever suas ações para com o outro, assim a sua integração com a sociedade se fortalece, se refaz, mas não se desfaz.

b) Concepção da transformação: Outros centralizam o objetivo da Justiça Restaurativa na concepção da transformação. A Justiça restaurativa objetiva fazer com que as pessoas compreendam a si próprias e como se relacionam com os outros. Pallamolla (2009) defende que essa concepção se afasta das outras, pois concebe a Justiça Restaurativa como um estilo de vida. Dentro dessa concepção seria abolida a distinção de condutas consideradas como crimes, sendo que estas e outras condutas danosas estariam dentro de uma mesma significação.

c) Concepção do Encontro: A concepção do encontro é a que melhor espelha as ideias centrais do movimento, de acordo com Pallamolla (2009). Para a autora, o encontro permite que os envolvidos - ofensor, vítima e comunidade - possam decidir pela melhor solução acerca do fato ocorrido. Para tanto, devem se encontrar em locais mais informais e com diminuição de figuras autoritárias e de autoridade, como são fóruns e tribunais organizados no formato de atual.

As três concepções aqui explicadas estão contidas dentro do movimento restaurativo mesmo apresentando diferenças umas com relação às outras, e mesmo sendo utilizadas respectivamente em maior ou menor medida, a depender do conceito elaborado por cada autor e da demanda do caso concreto. 
Este apanhado conceitual é um pouco do que é a justiça restaurativa e do que ela pode vir a fomentar se efetivamente tornar-se uma prática no sistema de justiça brasileiro, atendendo a diversos casos e situações no âmbito penal e penal juvenil, podendo ser uma possibilidade de mudança no pensamento social e jurídico com relação aos conflitos penais. Pode ser a contribuição para o alcance de uma das liberdades associadas ${ }^{5}$, no caso o acesso à justiça qualificada, a qual corrobora significativamente para o alcance do objetivo maior que é o direito humano ao desenvolvimento.

\subsection{Justiça restaurativa, um outro olhar sobre acesso à justiça}

A Constituição Cidadã de 1988, traz em seu artigo $5^{\circ}$, incisos XXXV e LXXIV ${ }^{6}$, a garantia constitucional do acesso à justiça a partir do princípio da inafastabilidade da jurisdição e da assistência judiciária, e também no artigo $8^{\circ}$ da Convenção Interamericana sobre Direitos Humanos de São José da Costa Rica, do qual o Brasil é signatário. ${ }^{7}$

A partir desses elementos normativos, entende-se que o Brasil fomenta legislativamente o princípio de acesso à justiça com relevância constitucional. Nesse contexto, a partir das ideias de desenvolvimento humano e sustentável latente a partir dos nos anos 80, a construção de um acesso qualificado à justiça, com adequação de soluções judiciais e extrajudiciais aos conflitos possibilitou a inserção das concepções restaurativas em afloração nos anos 80 e 90.

Nesse sentido, o Governo Federal ao perceber ao longo dos anos a importância da Justiça Restaurativa, fomentada em tratados internacionais, aprovou o $3^{\circ}$ Programa Nacional de Direitos Humanos (PNDH-3), por meio do Decreto $n^{\circ}$ 7.037, de 21/12/2009, posteriormente atualizado pelo Decreto $\mathrm{n}^{\mathrm{o}}$ 7.177. O decreto determinou como um dos objetivos "incentivar projetos pilotos de Justiça Restaurativa, como forma de analisar seu

\footnotetext{
${ }^{5}$ Conceito de Amartya Sen (2000) trazido por Anjos Filho (2013, p. 50), liberdades associadas (participação política, poder se expressar livremente etc.) fazem parte da concepção de liberdades substantivas, as quais incluem tanto aquelas quanto as liberdades elementares (condições de evitar fome, subnutrição, mortandade prematura etc.).

${ }^{6}$ Constituição Federal 1988. Art. $5^{\circ}$ - Todos são iguais perante a lei, sem distinção de qualquer natureza, garantindo-se aos brasileiros e aos estrangeiros residentes no País a inviolabilidade do direito à vida, à liberdade, à igualdade, à segurança e à propriedade, nos termos seguintes: [...] XXXV - a lei não excluirá da apreciação do Poder Judiciário lesão ou ameaça a direito; [...] LXXIV - o Estado prestará assistência jurídica integral e gratuita aos que comprovarem insuficiência de recursos.

${ }^{7}$ Convenção Interamericana sobre Direitos Humanos de São José da Costa Rica. Art. $8^{\circ}$. Toda pessoa tem direito de ser ouvida, com as garantias e dentro de um prazo razoável, por um juiz ou tribunal competente, independente e imparcial, estabelecido anteriormente por lei, na apuração de qualquer acusação penal contra ela, ou para que se determinem seus direitos ou obrigações de natureza civil, trabalhista, fiscal ou de qualquer natureza.
} 
impacto e sua aplicabilidade no sistema jurídico brasileiro", assim como "desenvolver ações nacionais de elaboração de estratégias de mediação de conflitos e de Justiça Restaurativa nas escolas".

A promoção de práticas restaurativas no país e no mundo está associada também ao fomento da nova visão do acesso à justiça, mais completo e por isso mais instruído, representando a vontade de desenvolver novas acepções sobre justiça. Nesse caminho, a justiça restaurativa vem como renovação do sentido de justiça, indo de encontro a racionalidade judicial tradicional. A saída encontrada pelo movimento restaurativo em geral é "trabalhar a compreensão das pessoas sobre a situação conflituosa para que haja humanização dos envolvidos" (AGUIAR, 2009, p. 109) para que se possa construir uma situação positiva e não estigmatizada e piorada pelos conservadores espaços judiciais.

Essa situação renovada apresentada pela justiça restaurativa corrobora com outros pontos importantes fomentados pelo direito ao desenvolvimento como a participação social e o poder de se expressar livremente. Assim, restaurar é encontrar dentro do conflito uma possibilidade de se fortalecer pessoalmente ou coletivamente, se responsabilizando pelos atos praticados de maneira positiva e não mais acoimada. Entende-se que é uma aproximação mais real do conceito de justiça. Haward Zehr (2008) explicita a justiça de forma a se aproximar dessas novas possibilidades, do acesso real à justiça, do desenvolvimento e dos direitos humanos: A justiça precisa ser vivida, e não simplesmente realizada por outros e
notificada por nós. Quando alguém simplesmente nos informa que foi feita a
justiça e que agora a vítima irá para casa e o ofensor para a cadeia, isto não
dá a sensação de justiça. Nem sempre é agradável vivenciar, passar pela
experiência da justiça. Mas ao menos saberemos que ela existiu porque
participamos dela ao invés de ter alguém a fazer isso por nós. Não é
suficiente que haja justiça, preciso vivenciar a justiça. (ZEHR, 2008, p. 191-
192)

Essa ideia transgressora e pertinente trazida por Zehr é uma utopia realizável e necessária para a nova conjuntura mundial, onde o Brasil tem relevância e assume, ao menos teoricamente, muitas das mudanças puxadas pelo direito humano ao desenvolvimento, especialmente no que diz respeito à justiça e ao combate à violência.

Em uma nova concepção do que é justo, a justiça restaurativa se instala num processo que demanda sujeitos atuantes e participantes na construção de uma subjetividade jurídica de alteridade, onde as comunidades denotam importância nesse caminho de libertação e humanização. Daniel Aragão (2004, p. 222) ao falar sobre a nova subjetividade jurídica e 
direitos em construção, acentua: nasce uma "subjetividade jurídica, marcada pela construção de direitos, como atuação do oprimido no seu processo de libertação", aqui entende-se práticas restaurativas também como meio de libertação do indivíduo em todos os seus papéis sociais, não somente no lugar do oprimido.

Rebouças (2010) também contribui para a compreensão de um novo sistema de resolução de conflitos, voltado para a construção coletiva, libertadora e participativa de direitos, pois entende que, muitas vezes, as questões judiciais dizem respeito mais à vida e às pessoas do que às leis e ao Estado, o quais

Diante do exposto, o acesso à justiça proporcionado pelo fenômeno restaurativo se insere no contexto atual e contemporâneo em que temas como direito humanos, combate à violência, desenvolvimento, filosofia da alteridade estão em destaque. Dentro do tema aqui delineado, a justiça restaurativa responde bem às políticas fomentadoras do acesso à justiça qualificado, tema tão discutido e ainda tão necessário, posto que sua prática, especialmente no Brasil, ainda não se consolidou, mesmo com todos os argumentos normativos e doutrinários existentes.

De outro modo, já existem práticas brasileiras de justiça restaurativa, umas ainda em fomento, outras já em execução, como a que se desenvolveu em São Caetano do Sul/SP, projeto piloto patrocinado pelo Ministério da Justiça, por meio do Programa das Nações Unidas - PNUD e pela Secretaria da Reforma do Judiciário. Outros projetos se desenrolaram sob a teoria restaurativa, em diversos estados: em Porto Alegre/RS, em Belo Horizonte/MG, em São José de Ribamar/MA e em Salvador/BA. O que mostra a abrangência da prática da justiça restaurativa.

Assim como apresenta Cappelletti e Garth (1988), Souza (2004) também entende que é pertinente essa tendência de se reformular a justiça, os três autores lançam mão dos mecanismos alternativos de justiça como maneira mais efetiva de desburocratizar e desjudicializar a prestação da justiça, o que se coaduna com a concepção de uma justiça melhor, mais eficaz, tempestiva e adequada aos conflitos.

\section{CONSIDERAÇÕES FINAIS}

$\mathrm{O}$ artigo aqui delineado tem o intuito de situar a justiça restaurativa, a partir de seu contexto histórico e acepções, para apresenta-la como aspecto prático do acesso qualificado à 
justiça na atualidade, com vistas à fraternidade buscada pelos defensores do direito ao desenvolvimento. É pertinente falar em uma renovação da justiça.

Este artigo se propôs a posicionar a justiça restaurativa como uma nova possibilidade de justiça, um novo olhar sobre o modo de resolver questões humanas, as quais possuem complexidade suficiente para negarem os meios tradicionais de justiça, os espaços e as autoridades. Não é negar ao juiz, ao tribunal e a audiência, até porque a cultura ainda não estaria consolidada para tanto, mas é permitir uma nova roupagem pertinente aos novos rumos mundiais de justiça e combate à violência.

O estudo aqui apresentado se pretende inicial, por outro lado não incompleto nesse momento atual do direito ao desenvolvimento. O objetivo foi posicionar dentro do direito ao desenvolvimento, o movimento restaurativo como qualificado e adequado acesso à justiça, mesmo diante dessa ausência de consolidação prática.

O direito ao desenvolvimento se estrutura em torno da humanidade e sustentabilidade das atividades que devem ser exercidas pelos Estados, pertinente ao modelo fraterno do qual ele participa. Nesse sentido, as concepções centrais de reparação, encontro e transformação defendidas pela justiça restaurativa se aproxima desse direito humano tão comentado e buscado, mas ainda em construção constante.

Transformar a vivência das pessoas para com a justiça é adequado e efetivo perante ao desejo de um acesso à justiça renovado que possa atender às necessidades das pessoas de forma digna e humana. Isto porque, são muito humanas, a liberdade e a oportunidade de ter poder sobre a própria vida e seus conflitos. Por isso, a justiça restaurativa propõe um acesso à justiça muita mais do que tempestivo, efetivo ou adequado, ela pode possibilitar a superação de si mesmo a partir do olhar para o outro e para o sofrimento, seguindo o caminho da alteridade, sem perder a essência pessoal e humana. No pensamento de Amartya, o alcance das liberdades, através das oportunidades elementares e associadas, é caminho para independência, é caminho para o mais completo desenvolvimento, porque das pessoas subjetivamente libertas, nascem as sociedades livres, humanas e fraternas.

\section{REFERÊNCIAS}

AGUIAR, Carla Zamith Boin. Mediação e Justiça restaurativa: A Humanização do Sistema Processual como forma de Realização dos Princípios Constitucionais. São Paulo/SP: Quartier Latin, 2009. 
ANJOS FILHO, Rogério Nunes do. Direito ao Desenvolvimento. São Paulo/SP: Saraiva, 2013.

APOLINÁRIO, Silvia Menicucci de Oliveira Selmi. Desenvolvimento sustentável na perspectiva da implementação dos direitos humanos (1986 - 1992). In: ALMEIDA, Guilherme Assis de; PERRONE-MOISÉS, Cláudia (Coords.). Direito internacional dos direitos humanos: instrumentos básicos. São Paulo/SP: Atlas, 2007. p. 74-98.

ARAGÃO, Daniel Maurício Cavalcante de. Subjetividade do Outro, processo de libertação e construção de direitos no contexto latino-americano. In: Wolkmer, Antônio Carlos (Org.).

Direitos Humanos e filosofia jurídica na América Latina. Rio de Janeiro/RJ: Lumen Juris, 2004. p. $211-228$.

BRASIL. Constituição: República Federativa do Brasil de 1988. Brasília, DF: Senado Federal, 1988.

Decreto 678 de 06 de novembro de 1992. Promulga a Convenção Americana sobre Direitos Humanos de 22 de novembro de 1969 (Pacto São José da Costa Rica). Diário Oficial da União de 09/11/1992, p. 15562. Brasília/DF: Presidência da República, 1992.

Decreto 7.037, de 21 de dezembro de 2009. Aprova o Programa Nacional de Direitos Humanos - PNDH - 3 e dá outras providências. Brasília. Diário Oficial da União de 22/12/2009, p. 17. Brasília/DF: Presidência da República, 2009.

CAPPELLETTI, Mauro; GARTH, Bryant. As soluções práticas para os problemas de acesso à justiça. In: Acesso à justiça. Tradução Ellen Gracie Northfleet. Porto Alegre/RS: Sergio Antônio Fabris Editor, 1988. p. 31-74.

CUNHA JÚNIOR, Dirley da. Curso de Direito Constitucional. Salvador: Editora Podivm, 2010.

FERRAZ, Leslie Shérida. Direitos humanos e acesso à justiça - uma análise empírica da tutela coletiva e dos juizados especiais cíveis no Brasil. In: BERTOLDI, Márcia Rodrigues; SPOSATO, Karyna Batista (Coords.). Direitos humanos: entre a utopia e a contemporaneidade. Belo Horizonte/MG: Fórum, 2011. p. 341-359.

JACCOUD, Mylène. Princípios, Tendências e Procedimentos que cercam a Justiça Restaurativa. Catherine Slakmon, Renato Campos De Vitto e Renato Sócrates Gomes Pinto (Org.). Justiça Restaurativa. Brasília: Ministério da Justiça e Programa das Nações Unidas para o Desenvolvimento, 2005. p. 163-188.

LEITE, Marta Franco; REBOUÇAS, Gabriela Maia. Desafios de um judiciário brasileiro em números: A Modernização a serviço de que(m)? In: CONGRESSO NACIONAL DO

CONPEDI, 24., 2015, Aracaju. Recurso eletrônico on-line. Florianópolis: CONPEDI, 2015. Disponível em: <

https://www.conpedi.org.br/publicacoes/c178h0tg/7z8sksbh/9wFg61Qyr8ddOx9s.pdf > Acesso em: 30 de julho de 2017. 
MACHADO, Carlos Augusto Alcântara. Constitucionalismo fraternal. Diálogos Possíveis; Ano 14, número 2, p. 3-19, jul. /dez. 2015. Acessado em 10 de junho de 2017. Disponível em: <http://faculdadesocial.edu.br/revistas/index.php/dialogospossiveis/article/view/307>

ONU. Declaração sobre o Direito ao Desenvolvimento. Adotada pela Resolução n. ${ }^{\circ}$ 41/128 da Assembleia Geral das Nações Unidas, de 4 de dezembro de 1986. Disponível em: < http://www.direitoshumanos.usp.br/index.php/Direito-ao-Desenvolvimento/declaracao sobreo-direito-ao-desenvolvimento.html>, acesso em 08 de junho de 2017.

PALLAMOLLA, Raffaella Porciuncula. Justiça Restaurativa: da teoria à prática. São Paulo: Ibccrim, 2009.

REBOUÇAS, Gabriela Maia; SPOSATO, Karyna Batista. As Lentes de uma justiça restaurativa no Brasil: observando experiências renovadas de acesso à justiça para o incremento do bebate. In: CONGRESSO NACIONAL DO CONPEDI, 19., 2010, Florianópolis. Anais eletrônicos. Florianópolis: Fundação Boiteux, 2010. Disponível em: < https://www.conpedi.org.br/publicacoes/c178h0tg/7z8sksbh/9wFg61Qyr8ddOx9s.pdf> Acesso em: 30 de julho de 2017.

REBOUÇAS, Gabriela Maia. Tramas entre subjetividades e direito: a constituição do sujeito em Michel Foucault e os sistemas de resolução de conflitos. Recife: O Autor, 2010.

SACHS, Ignacy. Ecodesenvolvimento: crescer sem destruir. São Paulo: Vértice, 1986. SACHS, Ignacy. O Desenvolvimento sustentável: do conceito à ação, de Estocolmo a Joanesburgo. P. 26-34. In: VARELLA, Marcelo Dias; BARROS-PLATIAU, Ana Flávia. Proteção Internacional do Meio Ambiente. Brasília: Unitar, 2009.

SEN, Amartya Kumar. Desenvolvimento como liberdade. Tradução Laura Teixeira Motta. São Paulo: Companhia das Letras, 2000.

SICA, Leonardo. Justiça Restaurativa e Mediação Penal: o Novo Modelo de Justiça Criminal e de Gestão do Crime. Rio de Janeiro: Lumen Juris, 2007.

SOUZA, Thaisa de. Justiça Comunitária: práticas de democracia participativa na América Latina. In: Wolkmer, Antônio Carlos (Org.). Direitos Humanos e filosofia jurídica na América Latina. Rio de Janeiro/RJ: Lumen Juris, 2004. p. 327 - 358.

ZEHR, Howard. Trocando as lentes: um novo foco sobre o crime e a justiça. São Paulo: Palas Athena, 2008.

Teoria e Prática: Justiça Restaurativa. São Paulo: Palas Athena, 2012. 